\title{
ISS Internal Active Thermal Control System (IATCS) Coolant Remediation Project - 2006 Update
}

\author{
Russell H. Morrison \\ The Boeing Company \\ Mike Holt \\ NASA Marshall Space Flight Center
}

\begin{abstract}
The IATCS coolant has experienced a number of anomalies in the time since the US Lab was first activated on Flight $5 \mathrm{~A}$ in February 2001. These have included: 1) a decrease in coolant $\mathrm{pH}, 2$ ) increases in inorganic carbon, 3) a reduction in phosphate concentration, 4) an increase in dissolved nickel and precipitation of nickel salts, and 5) increases in microbial concentration. These anomalies represent some risk to the system, have been implicated in some hardware failures and are suspect in others. The ISS program has conducted extensive investigations of the causes and effects of these anomalies and has developed a comprehensive program to remediate the coolant chemistry of the on-orbit system as well as provide a robust and compatible coolant solution for the hardware yet to be delivered. This paper presents a status of the coolant stability over the past year as well as results from destructive analyses of hardware removed from the onorbit system and the current approach to coolant remediation.
\end{abstract}

\section{INTRODUCTION}

The International Space Station (ISS) is under construction in low earth orbit by an international consortium led by the National Aeronautics and Space Administration (NASA) of the United States. On-orbit assembly began in 1998 with the launch of the Russian Zarya Module (aka Functional Cargo Block (FGB)). Active cooling of the internal elements of the United States On-Orbit Segment (USOS) of ISS began in February 2001 when the U. S. Laboratory (US Lab) Module was launched on STS-98 and docked to the Unity Module (aka Node 1).

Active cooling of power components, avionics, experiments and the environmental control elements in the US Lab and other pressurized elements of the USOS is provided by a pumped water system that rejects heat by way of an interface heat exchanger to an ammonia system and radiators mounted on the external truss elements of the ISS. There are two cooling loops currently on orbit. One controls temperature to about $40^{\circ} \mathrm{F}$ and is called the low temperature loop (LTL). The second controls temperature to about $60^{\circ} \mathrm{F}$ and is called the moderate temperature loop (MTL) [1].

The ISS Internal Active Thermal Control System (IATCS) coolant is an aqueous solution controlled by SSP 30573 , Space Station Program Fluid Procurement and Use Control Specification, Table 4.1-2.8 Heat Transport Fluid (IATCS). Previous work [2] has described the mechanism and effects of permeation of flexhoses and gas traps by oxygen. Revision B of SSP 30573 does the following to limit corrosion and microbial growth in or on the IATCS primary materials of construction (CRES 347, Ni 201, BNi-2 braze, BNi-3 braze, Teflon, titanium, electroless nickel).

1. Chlorides are limited to less than $1.0 \mathrm{ppm}$ max in response to testing which has shown clear evidence of pitting corrosion to the primary materials of construction in the IATCS.

2. $\mathrm{pH}$ is adjusted to $9.5+/-0.5$ with sodium hydroxide to slow corrosion and limit microbial growth.

3. Sodium borate (800-1200 ppm as B4O7) is added to provide a buffer for $\mathrm{pH}$ control.

4. Di- or tri-sodium phosphate (200-250 ppm as PO4) was added to boost corrosion resistance in the CRES as compensation for moving away from a deoxygenated coolant. In retrospect, this was an unnecessary move with negative solubility impacts.

5. Dissolved oxygen is controlled to $>6 \mathrm{ppm}$ to protect oxide passivation of metallic surfaces.

6. Total organic carbon is held to less than $5 \mathrm{ppm}$ to limit the food supply for microbes.

7. Silver ions are added in the form of silver sulfate $(0.1$ to $3 \mathrm{ppm}$ ) as an anti-microbial.

Previous work [2] has also described how early program decisions on the use of gas permeable Teflon flexhoses in the IATCS coolant system and the unexpected effects of higher on-orbit $\mathrm{CO}_{2}$ levels have resulted in a lowered coolant $\mathrm{pH}$. This has led to increased rates of corrosion 
in nickel brazed and electroless nickel plated hardware throughout the system. There have been consequent nickel precipitation events, primarily nickel phosphate and/or nickel hydroxide, that have affected component performance.

The silver ions plate out of the coolant within days to weeks of being added and are rendered ineffective as an anti-microbial. This has created increased levels of planktonic and biofilm associated microorganisms.

Hardware returned on flight LF-1 in August 2005 have given the program new insights to the effects of these changes in the coolant chemistry on the IATCS subsystem components. This paper updates the on-orbit chemistry behavior since inception with most recent data. It presents a compilation of the known subsystem impacts attributable to coolant chemistry, and, finally, it presents the current status of the program defining the methods by which the coolant chemistry will be remediated and stabilized.

\section{ON-ORBIT COOLANT CHANGES}

The Teflon flexhoses are permeable to $\mathrm{CO}_{2}$. The elevated $\mathrm{CO}_{2}$ levels in the on-orbit atmosphere have caused increases in total inorganic carbon (TIC) to levels on the order of $200 \mathrm{ppm}$ in the coolant. The $\mathrm{CO}_{2}$ has also caused a reduction in coolant $\mathrm{pH}$, Figure 1 . The $\mathrm{pH}$ has been fairly stable in the range of 8.4 to 8.5 since flight 8A in 2002.

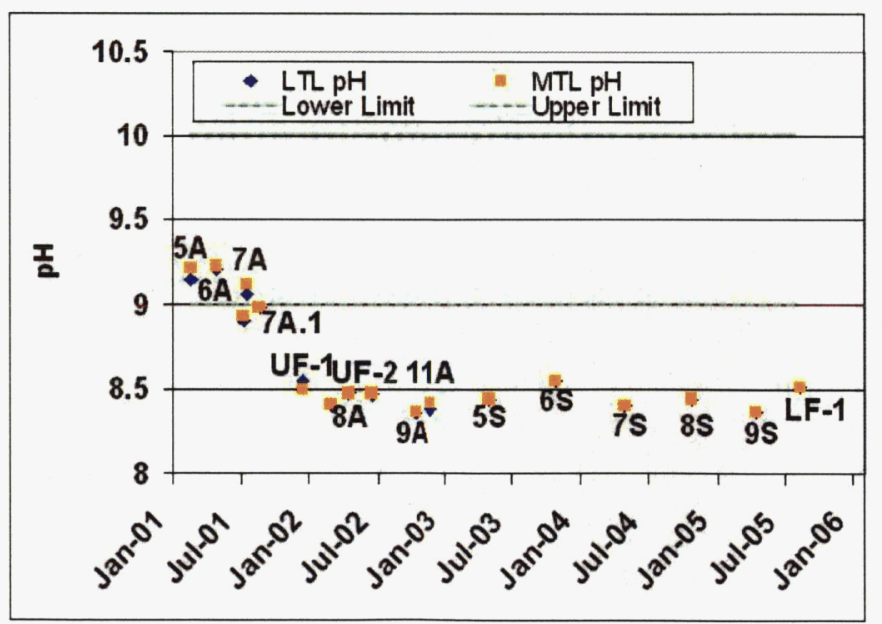

Figure 1. Coolant pH as measured in coolant samples returned from ISS for ground analysis

The decrease in $\mathrm{pH}$ has been accompanied by an increase in dissolved nickel ions within the coolant as illustrated in Figure 2. Nickel concentration in the coolant has increased at a rate of roughly $2.3 \mathrm{ppm}$ per year since late 2003.

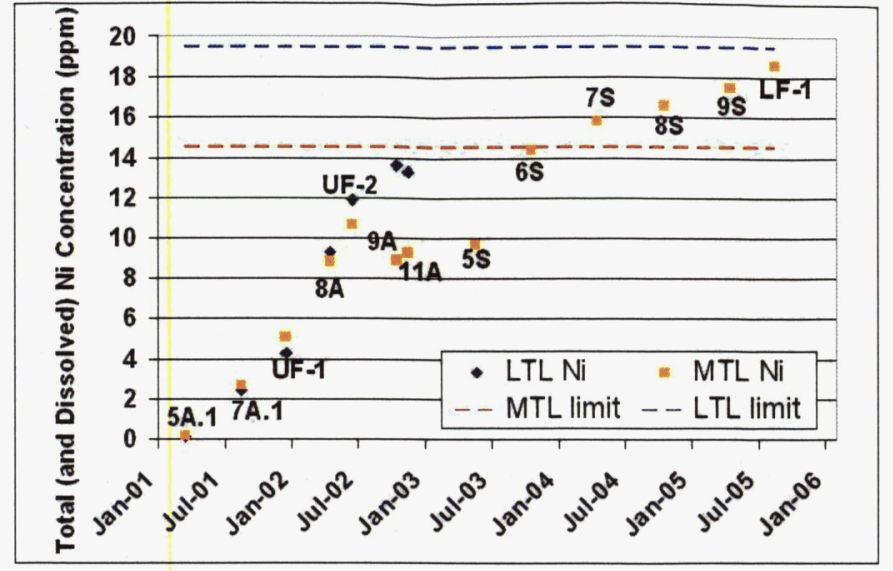

Figure 2. Total (approximately equal to dissolved) nickel concentration as measured in ISS coolant samples returned to ground for analysis

As the $\mathrm{pH}$ decreased and the nickel ion concentration increased, the point was finally reached when the phosphate in the coolant began to combine with the nickel to precipitate as nickel phosphate. The falling phosphate concentration is illustrated in Figure 3 . It has been fairly stable since bottoming out at about $10 \mathrm{ppm}$ in early 2005.

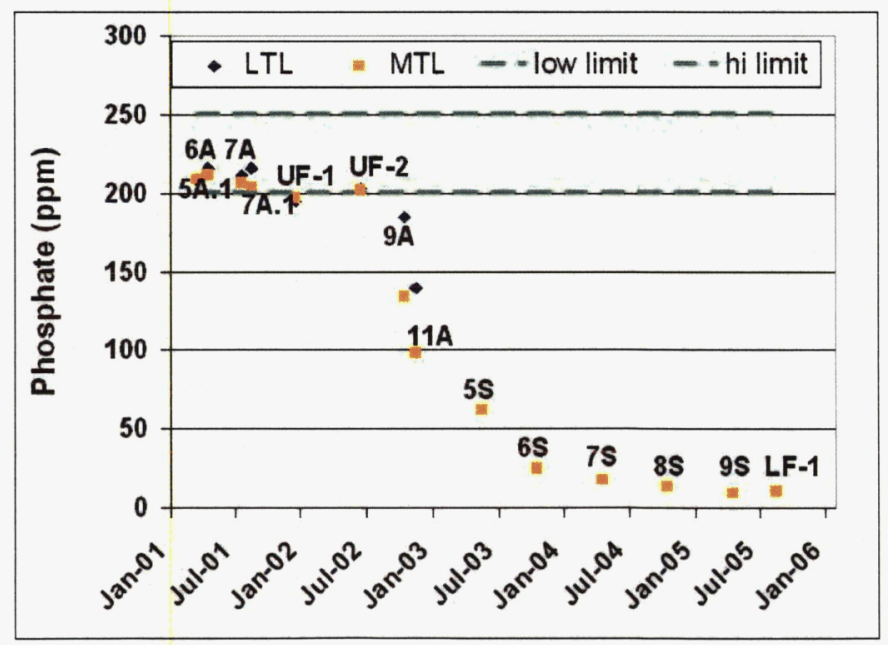

Figure 3. Phosphate concentration as measured in ISS coolant samples returned to ground for analysis

The planktonic microbial population, as measured in coolant samples returned from orbit, has been elevated since flight 7A in July 2001, Figure 4. Counts as high as $1.4 \mathrm{E}+07$ colony forming units (CFU) per 100 milliliters $(\mathrm{ml})$ were measured on flight $11 \mathrm{~A}$. There has been a steady slow decline in the counts measured in coolant samples since flight $5 S$ to the current level of $6.3 E+05$ $\mathrm{CFU} / \mathrm{ml}$. 


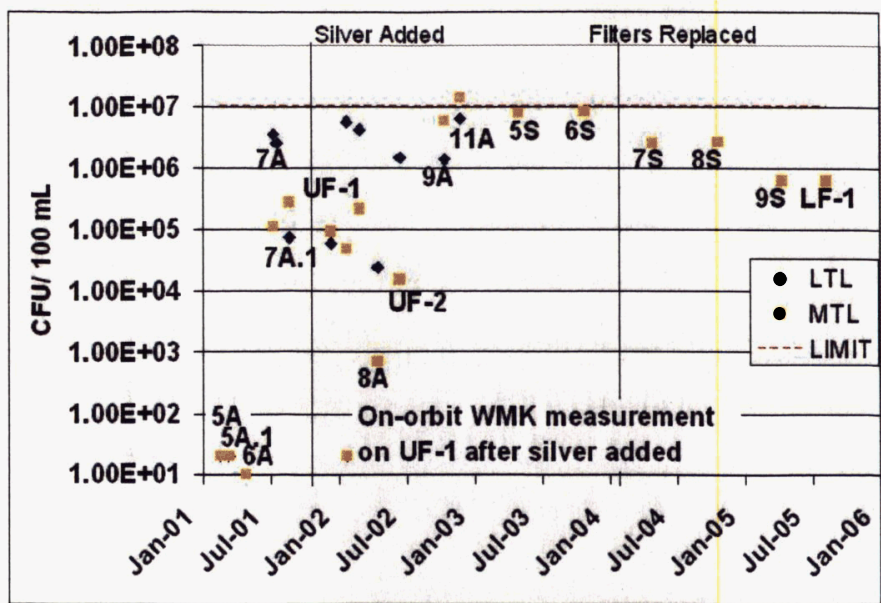

Figure 4. Planktonic microbial heterotrophic plate counts on R2A Agar as measured in ISS coolant samples returned to ground for analysis

\section{CONSEQUENCES OF COOLANT CHEMISTRY CHANGES}

The principal effect of the changes in chemistry has been the corrosion of nickel braze and electroless nickel surfaces in heat exchangers, coldplates and quick disconnects. While this implies a risk of coolant leakage due to a hardware penetration, no leak due to corrosion has yet been detected. Considerable effort has gone into predicting hardware life as it is affected by the increased corrosion rate. The hardware returned on flight LF-1 has permitted refinement of earlier predictions which were based entirely on ground testing.

A secondary effect has been precipitation of nickel compounds on different surfaces within the IATCS. This has resulted in several hardware failures and is suspect in others.

The planktonic bacterial populations measured to date do not directly affect the functionality of the IATCS equipment. Bacterial effects on the crew in the event of exposure to the coolant by accidental ingestion or inhalation become more of a concern. These levels of planktonic microorganisms in the coolant are also capable of supporting biofilm formation on the wetted surfaces of the IATCS. These biofilms may actually represent a majority of the microbial biomass in a recirculated low nutrient system [3]. This could interfere with heat transfer or coolant flow. It could serve as nucleation sites for nickel precipitate formation. It could harbor microenvironments conducive to the growth of anaerobic bacteria or acid-producing bacteria capable of accelerating corrosion or pitting. The pits formed in the nickel braze by chemical corrosion of the non-diffused intermetallic nickel are suspected of being conducive to the formation of such microenvironments. Considerable effort has been expended in ground testing to determine the possibility of microbially influenced corrosion in the on-orbit chemistry and with the microbial species known to be in the coolant. The hardware returned on flight LF-
1 has provided some long-needed insight to the actual effects of microbes on the on-orbit hardware.

The principal coolant related anomalies and the new information coming from assessments of the hardware returned on LF-1 are described below.

\section{GREEN GAS TRAP, JULY 2001}

The effects of nickel precipitation were believed to be first observed in the IATCS in July 2001 when the pressure drop across a gas trap installed in the MTL had risen to 6 psid from a nominal 4.4 psid last observed in November 1999 [4]. The pressure drop across this gas trap had been rising even during ground testing of the US Lab. The last pressure drop observed on the ground before launch was 5.3 psid in September 2000 . The US Lab was activated on-orbit in February 2001 and by May 2001, the gas trap pressure drop had risen to 5.7 psid. It was returned to the ground in August 2001. The hydrophilic membranes had a green appearance as illustrated in Figure 5, rather than the normal white. Tests revealed no significant microbiological contamination. Flushing with de-ionized water, isopropyl alcohol, and dilute hydrochloric acid cleaned the membrane module. At the time of its removal, the $\mathrm{pH}$ of the IATCS coolant was still around 9 and had never been below 9 . Phosphate concentration was still in the normal range. Nickel concentration in the coolant was still below $2 \mathrm{ppm}$ and was never high when the first increases in pressure drop were observed on the ground. Analysis of contamination from the membrane did reveal some nickel, phosphorus, silicon, aluminum and oxygen. It is not clear that these compounds were in large enough quantities to be responsible for the pressure drop observed. It is interesting that even in the surge of nickel phosphate precipitation that occurred over an 18 month period beginning in March 2002, it was not until one year into the process that the MTL gas trap pressure drop again reached 6 psid. Chemical modeling of the coolant and the fact that it cleaned up with dilute acid suggests that the contaminant was likely nickel hydroxide. It is not completely clear what role nickel precipitation played in the gas trap failure of July 2001, but it did alert the program to potential issues with nickel precipitates in the months to come.

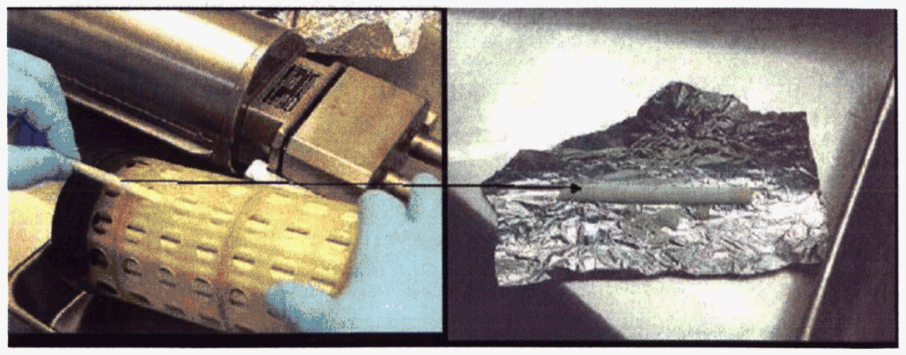

Figure 5. "Green Gas Trap" - contaminated with nickel precipitates

GREEN FILTER, OCTOBER 2002 
This filter was installed on the MTL in January 2002 after having been seeded with silver phosphate in an attempt to achieve some measure of microbiological control. After dissolution of the silver phosphate, pressure drop fell to the normal 1.9 psid. By October 2002, well into the main nickel phosphate precipitation event, the pressure drop in this filter had risen to 4 psid. It was replaced and returned on flight 9A. Green precipitate was quite obvious on this filter as seen in Figure 6 . Scanning Electron Microscopy/Energy Dispersive X-Ray Fluorescence (SEM/EDXRF) analysis clearly showed strong nickel and phosphate peaks. Fourier Transform Infrared (FTIR) spectrum analysis also closely matched that for nickel phosphate. This filter was clearly consumed due to nickel phosphate precipitation.

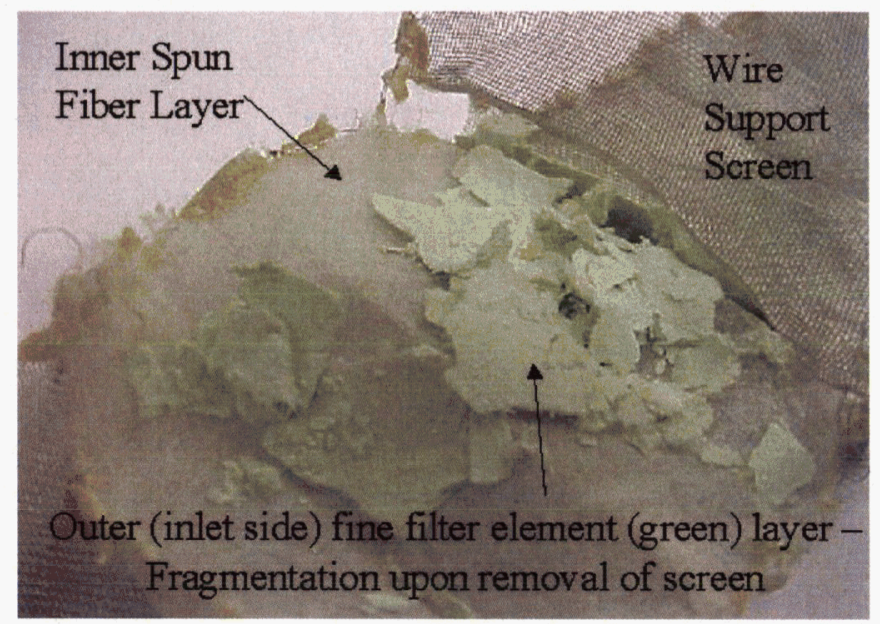

Figure 6. Green Filter - contaminated with nickel precipitates, primarily phosphate

\section{PUMP PACKAGE ASSEMBLY, MARCH 2003}

On March 16, 2003, after having experienced eight overcurrent spikes in an 8 hour period, the MTL pump package assembly (PPA) seized up and failed. From August 2002 until this time, the gas trap pressure drop on this PPA had risen from 4 to 6.6 psid. The filter pressure drop had not changed since its replacement in October 2002. This PPA was returned on flight LF-1 in August 2005 and subjected to test, teardown and evaluation in February and March 2006.

Nickel phosphate precipitates were found to have blocked passages providing flow and cooling to the hydrodynamic and hydrostatic bearings of the pump rotor assembly. Figure 7 is a cross-section of the rotating assembly with the coolant flow passages highlighted in red.

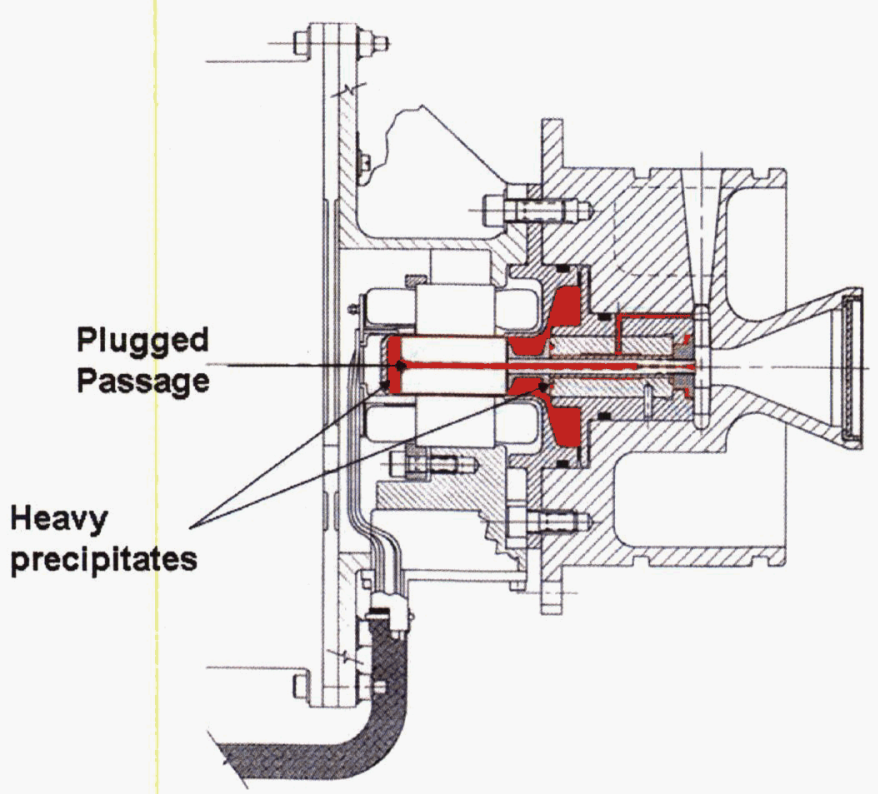

Figure 7. PPA cross-section, bearing flow passages in red

Figure 8 is the entire rotor assembly after removal from the PPA with visible green precipitation on the rotor OD and at the end. Figure 9 shows precipitates found in the bottom of the rotor seal in the stator and Figure 10 shows the precipitate buildup on the end of the rotor (both on left side of red area in Figure 7).

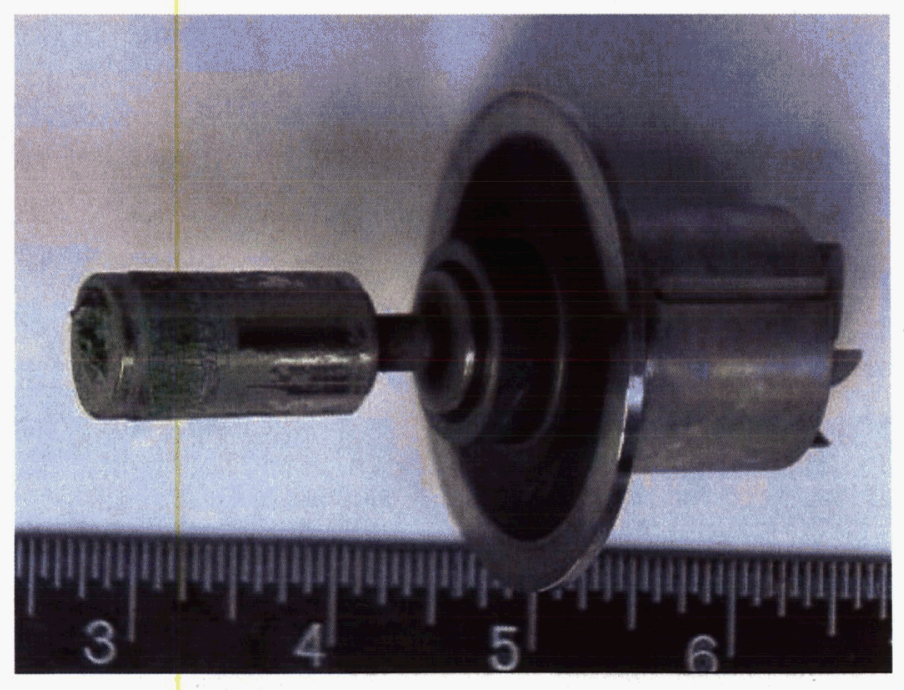

Figure 8. PPA Rotor Assembly 


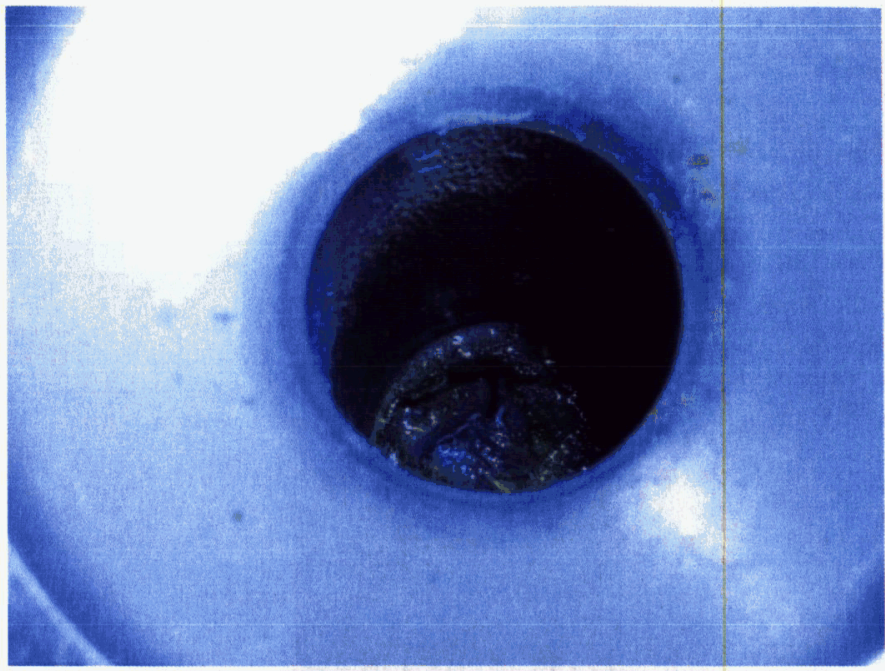

Figure 9. Precipitate in bottom of rotor cover well

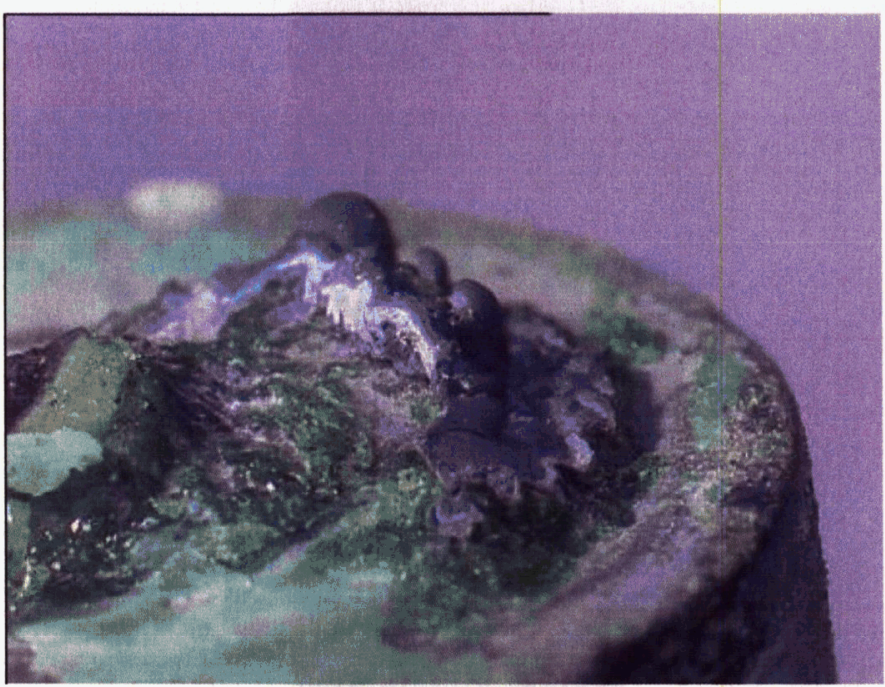

Figure 10. Precipitate on end of rotor

The precipitates were all positively identified as nickel phosphate by Scanning Electron Microscopy (SEM)/ Energy Dispersive Analysis X-ray (EDAX).

This failure occurred after about 9 months of rapidly decreasing phosphate concentration. The concentration was at about $75 \mathrm{ppm}$ and still over a year from stabilizing at about $10 \mathrm{ppm}$, thus there had been a large quantity of phosphate forming in the IATCS at the time the PPA failed. The PPA failure mechanism was loss of flow to the hydrodynamic and hydrostatic bearings due to a buildup of precipitates in the tight flow passages. Without flow, the hydrostatic thrust bearing collapsed and rotor torque exceeded the capability of the PPA motor. These MTL flow passages are among the warmest locations in both coolant loops. Nickel precipitates have an inverse solubility relationship to temperature, i.e. they are more likely to form at higher temperatures. Thus, these passages would have been among the most likely points in the loop for precipitation to first occur. As the passages became more and more restricted, the temperature of the coolant would have increased, exacerbating the rate of precipitate formation in the passages and accelerating the demise of the PPA.
Examination of the gas trap assembly from this PPA is expected to also reveal high concentrations of nickel phosphate. The current depleted state of phosphate in the on-orbit loops mitigates the risk to the operating pumps. No additional steps, beyond coolant remediation, are necessary to protect the US Lab coolant loops from this failure in the near future. This failure illustrates the need to keep phosphate out of the remaining coolant loops of future ISS elements.

\section{QUICK DISCONNECT (QD), FEBRUARY 2004}

A temporary reconfiguration of the coolant loops to support Soyuz vehicle relocation on ISS left four normally mated male and female QDs in a de-mated state for a period of approximately 56 hours. Two of the QD halves, one male, one female, had water blobs on their open faces totaling approximately $100 \mathrm{ml}$ just before they were re-mated. The male QD water blob is visible in Figure 11.

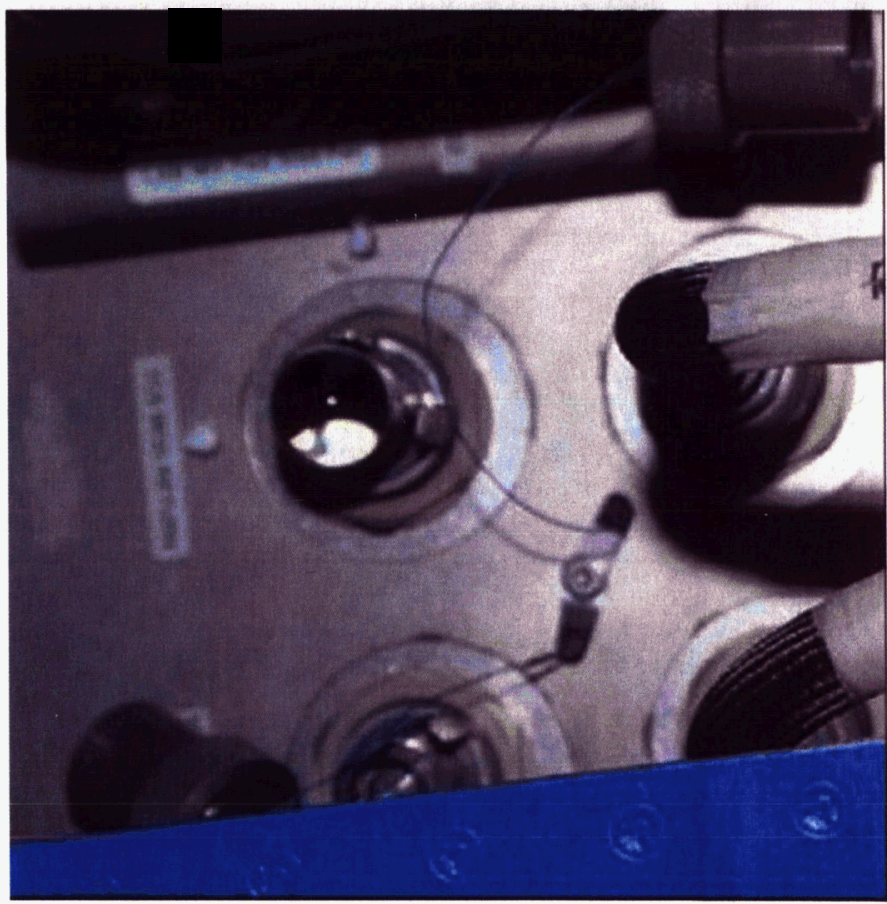

Figure 11. On-orbit QD leak

The female QD was removed as part of its hose assembly and returned on flight LF-1 for destructive analysis. The entire assembly including the female QD, male QD and flexhose were all carefully dissected and examined by staff from Montana State University (MSU) and the Center for Biofilm Engineering (CBE) in August and September 2005. The female QD was subjected to further examination by materials and processes staff of Boeing. Precipitate crystals were found on many surfaces of the flexhose and QDs as expected and as illustrated in Figures 12 and 13. These were examined by the Image and Chemical Analysis Laboratory at MSU using a number of techniques including: SEM/ Energy Dispersion X-Ray Fluorescence (EDXRF), X-Ray Diffraction (XRD) Spectrometer, Auger Electron 
Microprobe, Time-of-Flight Secondary Ion Mass Spectrometry (TOF SIM), and X-Ray Photoelectron Spectroscopy (XPS). These tests indicated that virtually all of the precipitate in the coolant system was nickel phosphate.

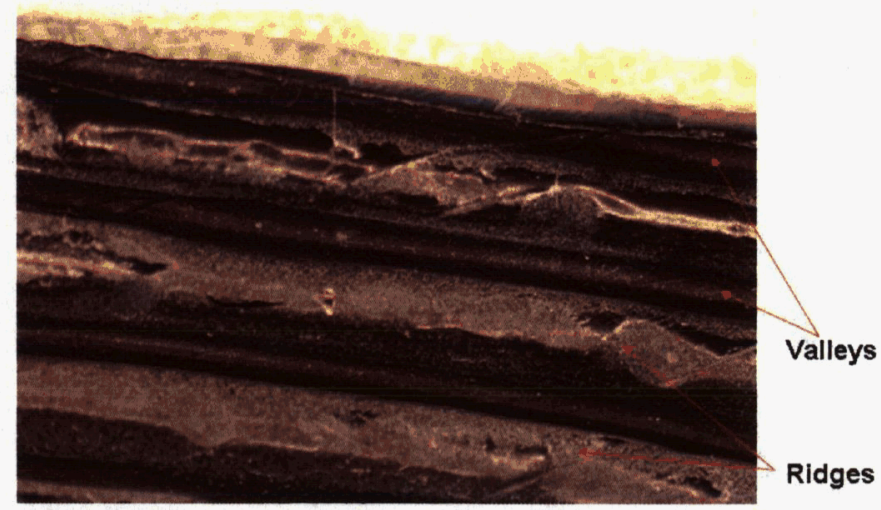

Figure 12. Valleys and ridges of flexhose returned on LF-1

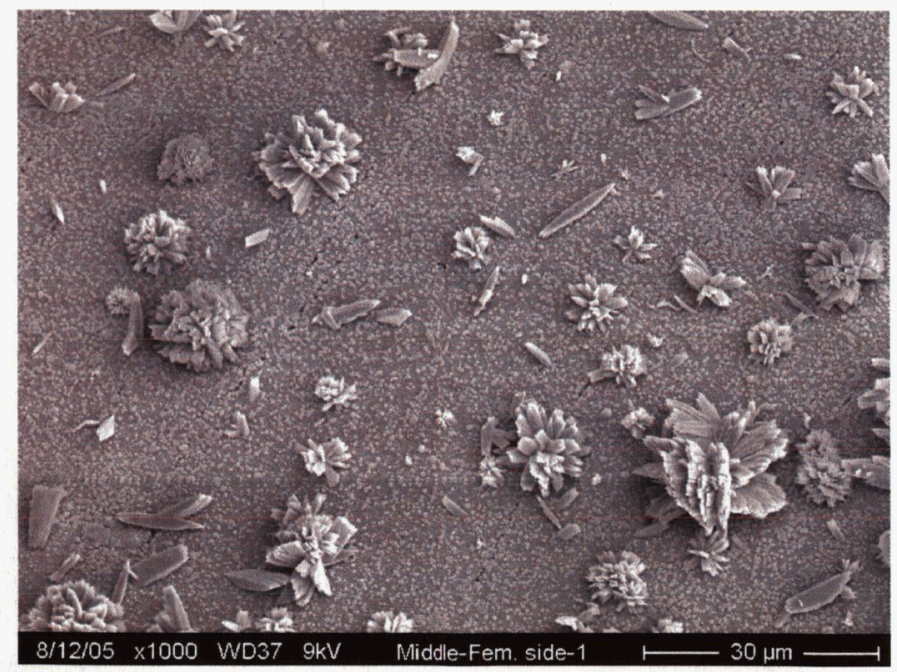

Figure 13. Heaviest distribution of precipitate, from center of teflon flexhose returned on LF-1, showing flowerettes of nickel phosphate

Fluid and surface swab samples for microbes from the flexhose and QDs were fundamentally in agreement with prior data in terms of species diversity and population. There were few surprises except for unexpectedly low surface bacteria counts and less biofilm than expected. Current speculation is that the nickel environment of the coolant and nickel surface deposits is toxic to microbes and inhibitory to most biofilm producing species.

Disassembly of the female $Q D$ revealed a modest buildup of coolant residues and precipitates on the seals and sliding parts, Figures 14 and 15 . There was no significant corrosion of the electroless nickel plated surfaces or any other surfaces in this $Q D$. The cause of leakage in the female QD is currently suspected to be low seat load at the stop plug after a de-mate cycle due to higher than normal friction between the OD of the female sleeve and the mating EPR o-ring in the housing brought on by deposition of coolant precipitates.

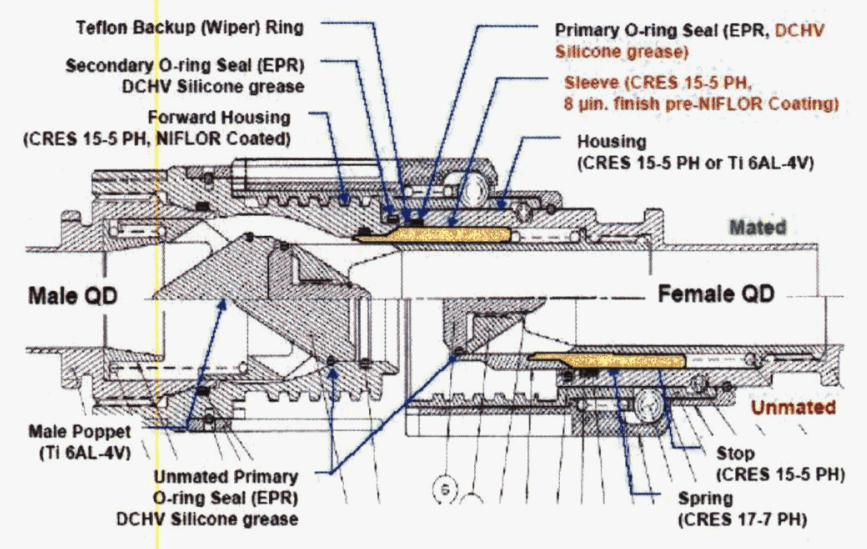

Figure 14. QD cross-section with sticking sleeve highlighted in yellow

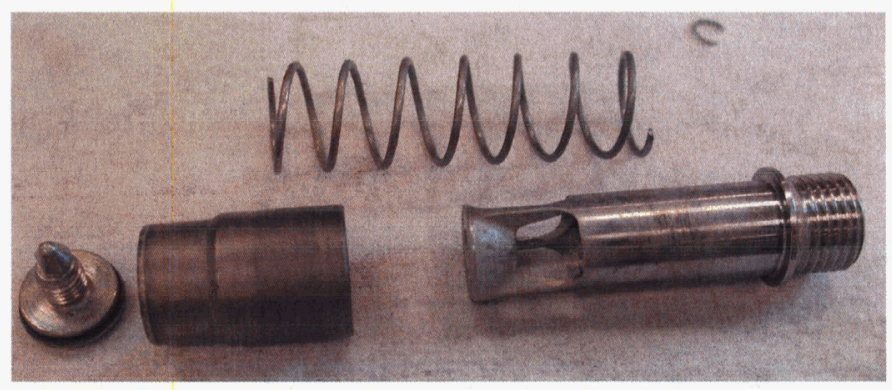

Figure 15. LF-1 female QD stop plug assembly

Procedural changes requiring the installation of caps or plugs on de-mated QD halves have been instituted. When this is not possible, the QD is cycled once before de-mating in the hopes of dislodging precipitate.

There have been five other QD failures on the ground in IATCS coolant service since February 2004. A $1 / 2$ inch female QD, S/N 1109, in the Human Research Facility 2 (HRF2) payload rack either closed very slowly or stuck open in October 2004. It stopped leaking after 4 open/close cycles with a male QD. It had been exposed to IATCS coolant for $\sim 2$ years.

Another $1 / 2$ inch female QD, S/N 1075, in the HRF prototype flight rack stuck open completely after 10 years service in IATCS coolant in September 2005. This unit had seen 3 weeks service in de-ionized water while mated to a Columbus Orbital Facility (COF) male QD in Bremen, Germany in April 2005. This exposure may have played a role in the failure of this unit, because the COF has experienced an extremely high failure rate in its QDs in 2005.

Three $1 / 2$ inch female QDs, S/Ns 1121, 1133, and 1134 , from the Japanese Experiment Module (JEM), all 
experienced very slow, small water leaks in March 2004 after approximately 5 years exposure to the IATCS coolant at $\mathrm{pH} 9.5$.

Active investigations continue for all these failed QDs. These investigations have revealed potential corrosion sensitivity in the electroless nickel plate on the OD of the female sleeve. These QDs are also intolerant of nickel deposits which can increase friction between the female sleeve and housing o-ring.

\section{SERVICING AND PERFORMANCE CHECKOUT UNIT (SPCU) HEAT EXCHANGER (HX) - MARCH 2005}

There are many components in the IATCS that contain nickel braze, but only a few represent potential catastrophic hazards. One is the SPCU HX that is installed in the USOS Airlock, Figure 16. This provides cooling for the Extravehicular Maneuvering Unit (EMU) when the crew is in the airlock. On the IATCS side of that $\mathrm{HX}$, the pressure is normally 40 to 60 psia but can be as high as 115 psia. The maximum allowable pressure on the EMU side is about 30 psia. The EMU side is not protected by a relief function at this time and, should it over-pressurize, the likely failure point is in the liquid cooled undergarment worn by the crewmember underneath the Extravehicular Activity (EVA) suit. There are times in the normal procedures when the crewmember is attached to the EMU side of the SPCU $\mathrm{HX}$ while suited up and at vacuum. A rupture of the undergarment at that time could result in up to one gallon of IATCS coolant spilling into the suit. The risk then is that the crewmember will inhale the coolant and drown. The corrosion study team predicted that the nickel braze layer in a normal SPCU HX can be penetrated in about 4 years at $\mathrm{pH} 8.3$ [5]. For that reason, the Airlock SPCU HX was replaced on March 15, 2005 with a spare unit that had undergone a second braze cycle and was expected to have a life in excess of 50 years.

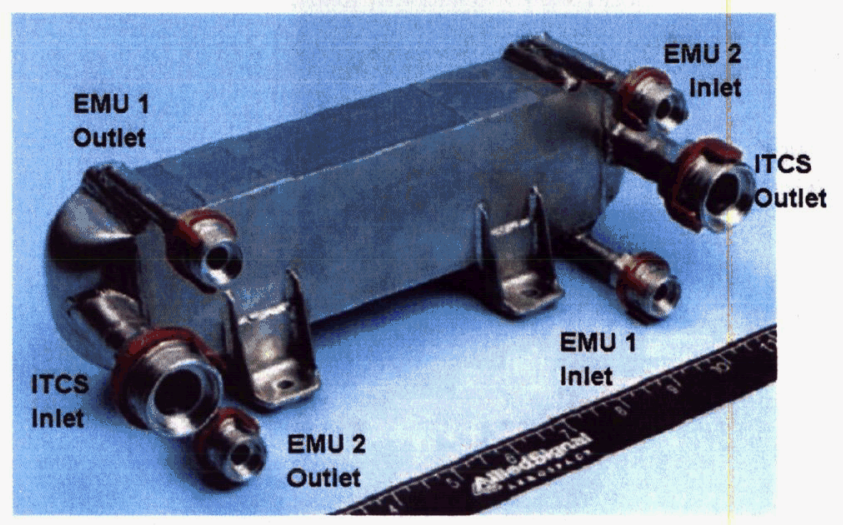

Figure 16. SPCU HX

The Airlock SPCU HX was then returned on flight LF-1 and subjected to sampling and dissection, first at Montana State University with additional dissection and analysis at Honeywell, Figure 17

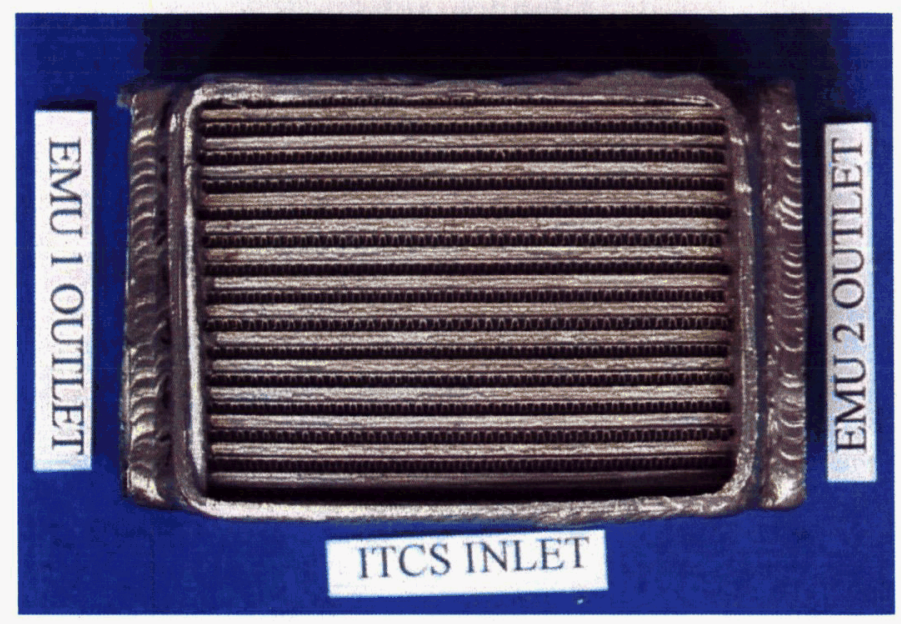

Figure 17. The ITCS passages of the dissected SPCU HX were visibly clean

Nickel phosphate particles under magnification were smaller and less abundant than those found in the flexhose returned on flight LF-1, Figure 18.

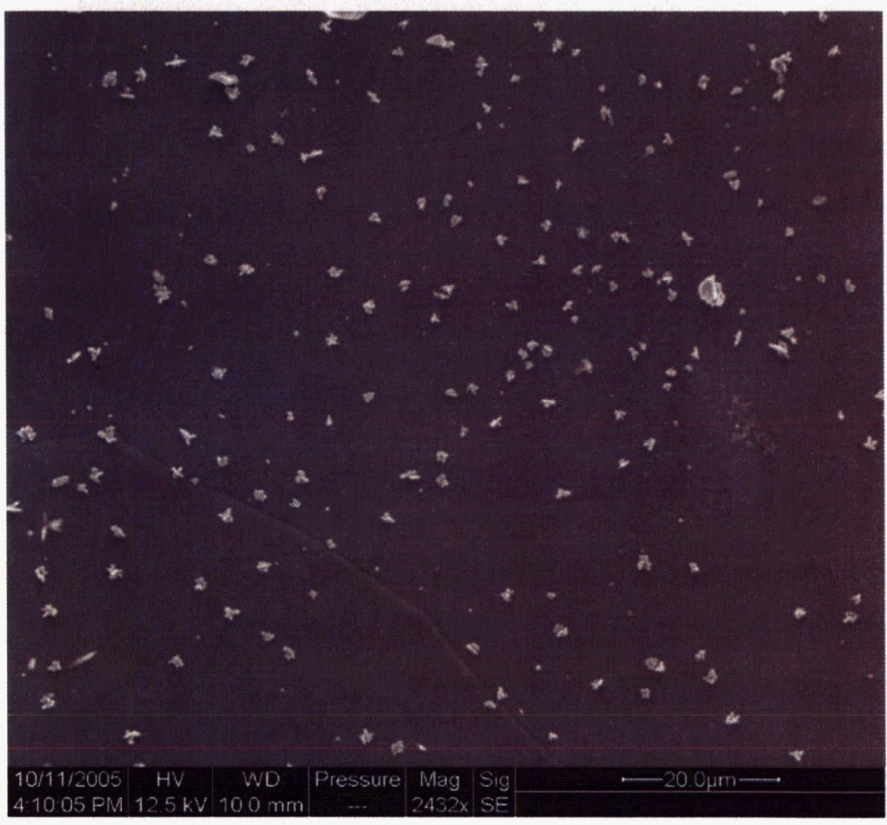

Figure 18. SPCU HX surface distribution of nickel phosphate

Microbial counts on the heat exchanger surfaces were less than expected. Nickel and nickel precipitates on the metal surfaces are suspected of inhibiting colony growth and biofilm formation much like in the QD and flexhose that was examined from LF-1.

This SPCU HX had been exposed to IATCS coolant at $\mathrm{pH}$ less than 9.0 for 3.75 years. New life calculations were made for all single braze cycle BNi-3 components like the SPCU HX based on microscopic examination of many cross-sections of the braze layer and heat exchanger parting sheet from this unit, Figure 19. The life of such components in IATCS coolant service was extended from 4 years to 16 years. This is the predicted 
time to penetrate the braze layer. Additional margin on life is contained in the underlying 0.006 inches of parting sheet.

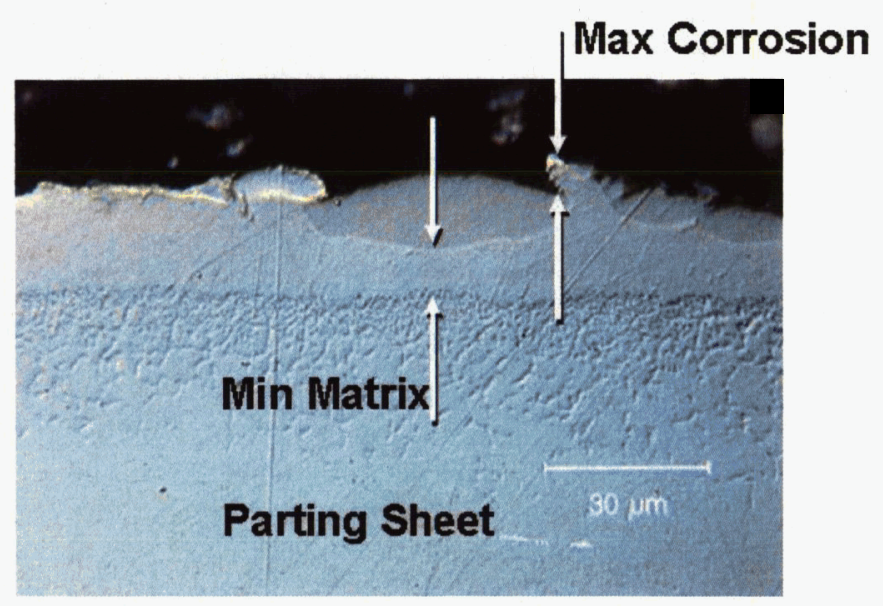

Figure 19. Braze cross-section with pure nickel matrix phase and faster corroding intermetallic phase nickel

Significantly greater evidence of corrosion was discovered in the EMU side of the SPCU HX. The coolant on this side is de-ionized water treated with iodine for microbial control. Crevice corrosion was found in one location on the EMU 1 loop. Insofar as the EMU coolant is quite different from the IATCS coolant, a full treatment of this corrosion phenomenon is beyond the scope of this paper. The EMU loop for the SPCU HX, with its tendency towards crevice corrosion, reduces the SPCU HX's life to only 8 years compared to the 16 years for other IATCS components. The corrosion team investigated the crevice corrosion phenomenon carefully and determined that crevice corrosion can be neither initiated nor sustained in the presence of the IATCS coolant.

The SPCU HX story is largely a "good news" story from the IATCS coolant perspective. It demonstrated that the earlier braze life predictions of the corrosion team based on ground testing were conservative and provided a basis for extending those estimates. It also provided sufficient evidence that the program could afford to wait on implementing an anti-microbial until full testing of a long-term anti-microbial solution could be completed.

\section{GAS TRAP, IN SERVICE}

The gas trap currently in service with the LTL PPA has had an increasing pressure drop since July 2003 [6]. It would normally be replaced before the pressure drop exceeded 6 psid, but since there have been no operations introducing gas to the IATCS loops and since there is a shortage of gas traps, this unit remains in service. This gas trap exceeded 6 psid in March 2004 and currently has a pressure drop on the order of 6.6 psid. Some fraction of the coolant flow is being bypassed around this gas trap due to the plugging. This condition poses no particular risk to the PPA or gas trap unless air is introduced to the loop. The program will continue to operate this gas trap until sufficient spare units are available. When air is expected to be introduced to the loop, the operations team temporarily activates the MTL PPA in single loop mode. This PPA has a fresh, fully functioning gas trap. The loops are run in Single MT mode until all the air is expelled from the loop and then the loop is reconfigured back to its normal Single LT mode of operation.

\section{COOLANT REMEDIATION}

The coolant chemistry effects to date have resulted in serious system and hardware anomalies as described above. It is the nature of the ISS program to be proactive in preventing problems and there are serious risks in allowing the coolant to continue its deviation from specified conditions. ISS efforts to manage the chemistry, on the other hand, have come close to exacerbating our problems rather than solving them as described in prior work [2]. As a result, the program has adopted a posture of requiring high fidelity tests of proposed solutions and withholding implementation until certain use criteria are met.

The program decided in 2004 that some combination of the following conditions would need to be met before authorizing implementation of a chemical solution to the presence of nickel and nickel precipitates:

1. Failure investigation of the following items shows that any nickel precipitates were a contributing cause to the failure
a. MTL PPA that failed in March 2003
b. The quick disconnect that leaked in February 2004
c. The Environmental Control and Life Support System (ECLSS) cabin air heat exchanger being returned on flight ULF1.1

2. Failure investigation of any failed gas traps or filters shows that nickel hydroxide or nickel carbonate were contributing causes to the failure (due to the potential ample supplies of these precipitates).

3. On-orbit data analysis indicates deleterious system symptoms such as reduced heat transfer rates or system flow and delta pressure degradation that can be traced to scale formation as evidenced in analysis of returned orbital hardware.

4. A hardware failure after September 2003 (when phosphate levels were low) is traced to nickel phosphate formation

It is clear, at this time, that the "1.a." and "1.b." criteria have been met. Pending successful completion of full scale system tests of the coolant remediation plan described herein, program authority to execute the plan is expected.

The ISS program is actively preparing solutions to the observed coolant anomalies. A strategy is currently in place to control the level of nickel present in the coolant and to remove phosphate. A buffer change has been 
identified which will provide for stable $\mathrm{pH}$ control in the 9 - 9.5 range. A new anti-microbial is undergoing a rigorous development program including: screens for effectiveness in the on-orbit coolant chemistry, material compatibility and interference with ammonia detection in the coolant; toxicology assessment; ECLSS compatibility assessment; and hazard control plan development. The key elements of the coolant remediation plan are summarized below.

\section{MODELING}

The IATCS coolant working group has enlisted the aid of specialists in the modeling of corrosion and water chemistry effects. Products of that effort, like the stability diagram in Figure 20, have proven invaluable in understanding observations from on-orbit coolant samples as well as those from tests performed on the ground at beaker, bench and full system levels. The models are refined with data and then used to predict the outcome of future tests and remediation efforts.

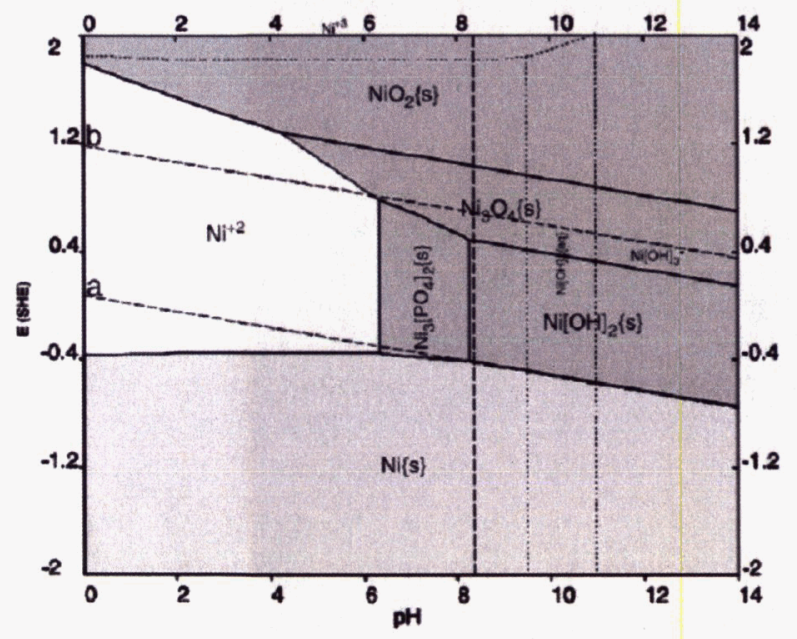

Figure 20. Nickel Pourbaix diagram for IATCS coolant showing that on-orbit equilibrium $\mathrm{pH}$ lies at boundary between nickel hydroxide and nickel phosphate formation

\section{NICKEL REMOVAL ASSEMBLY (NIRA)}

The IATCS coolant working group has performed extensive experimentation and perfected the application of a chelating resin produced by DOW Chemical for the removal of nickel ions from the IATCS coolant. A recirculating bench test of the NiRA performed in 2003/4 demonstrated its effectiveness at reducing nickel concentration, Figure 21. As the nickel concentration drops, nickel phosphate crystals distributed throughout the test bed were observed to re-dissolve and phosphate concentrations returned to their pre-precipitated levels. Subsequent bench testing proved the effectiveness of additional resin treatments for maintaining a constant $\mathrm{pH}$ during NiRA implementation. Ground NiRA units have been produced for experimentation and to support nickel ion removal from the Node 2 cooling systems while it is processed at the NASA Kennedy Space Center (KSC). Flight units have been delivered to NASA KSC and are scheduled to be carried to orbit on flight 12A.1, Figure 22.

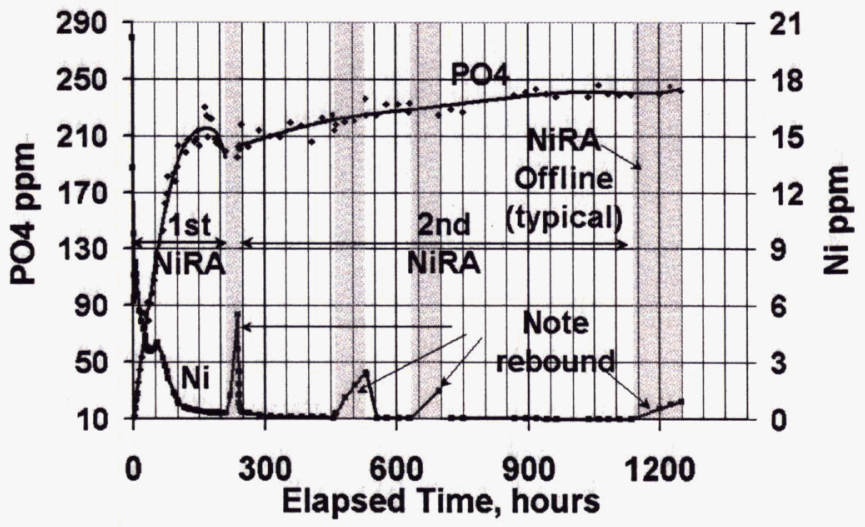

Figure 21. Recirculating bench test results of NiRA showing nickel removal (green) and phosphate redissolution (orange)

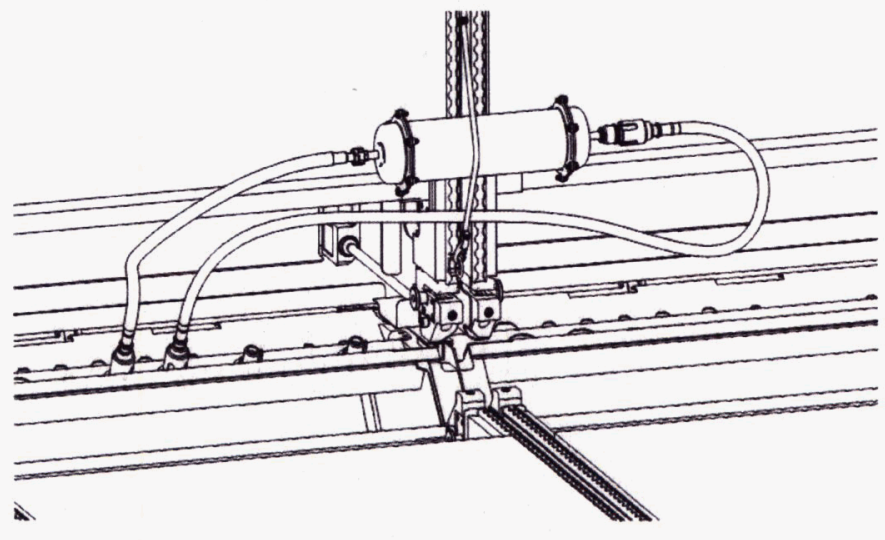

Figure 22. NiRA canister installed in US Lab

\section{PHOSPHATE REMOVAL ASSEMBLY (PHOSRA)}

Phosphate was added to the coolant primarily as a corrosion inhibitor for the stainless steels in the system. Corrosion testing has shown that this is unnecessary at the $\mathrm{pH}$ levels the coolant is experiencing. Its propensity for forming nickel phosphate at the equilibrium $\mathrm{pH}$ of the on-orbit coolant has provided motivation to eliminate it. Future elements of the IATCS will be launched with coolant that has no phosphate. In order that payload racks may be freely moved between the US Lab and other on-orbit elements, and to preclude future nickel phosphate formation, it will be necessary to remove the phosphate from the US Lab coolant. To that end, the program has completed an extensive development program to adapt a DOWEX ion exchange resin to this application. Figure 23 illustrates its effectiveness at the bench level for phosphate removal without perturbing $\mathrm{pH}$. Two flight units of the PhosRA, based on the NiRA 
design, have been fabricated and were delivered in January 2006.

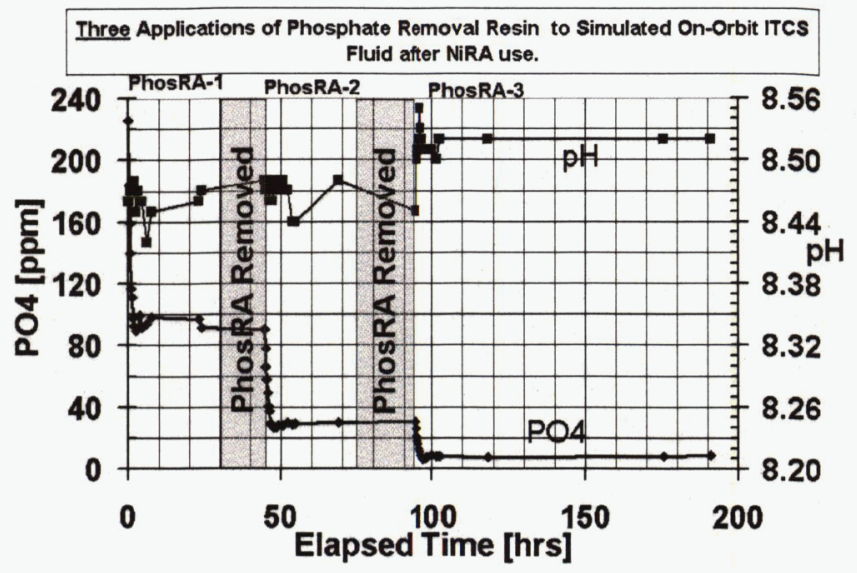

Figure 23. Bench scale testing of PhosRA resin showing phosphate removal effectiveness and ability to maintain a relatively constant $\mathrm{pH}$

\section{BUFFER SYSTEM}

Corrosion testing of the nickel brazed components of the IATCS has shown that $\mathrm{pH}$ is the most significant factor in controlling the corrosion rate of that hardware [5]. $\mathrm{pH}$ conditions less than 9.5 have a significant effect on the corrosion performance of $\mathrm{BN}-2$ and $\mathrm{BNi}-3$ alloys, with the biggest increase in corrosion occurring with the drop in $\mathrm{pH}$ from 8.3 to 7.3 .

Laboratory testing has shown that addition of 0.04 equimolar carbonate / bicarbonate buffer to the 1000 ppm borate buffer already in the on-orbit US Lab coolant after pre-treatment with NiRA and PhosRA will raise the $\mathrm{pH}$ to about 9.5. Equilibration of the coolant with the $\mathrm{CO} 2$ in the US Lab atmosphere will lower the $\mathrm{pH}$ to between 9 and 9.1, Figure 24 .

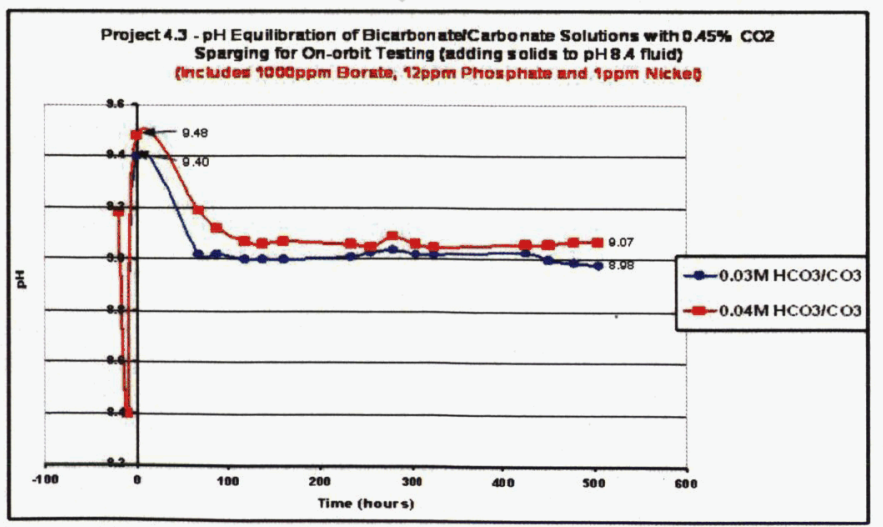

Figure 24. 0.04 molar carbonate / bicarbonate (red) $\mathrm{pH}$ vs time while being sparged with air/CO2 at US Lab concentrations

This synergy between the buffer and the natural US Lab atmosphere to control the coolant $\mathrm{pH}$ is a valuable innovation. It insures the long term stability of the coolant buffer system. A stable increase in the coolant $\mathrm{pH}$ to above 9 has a beneficial effect on the life of braze components and significantly limits the amount of nickel corrosion products released into the coolant from intermetallic phase corrosion. This holds the promise of extending IATCS hardware life beyond the service life of the ISS and greatly reducing the need to use NiRAs for routine on-orbit nickel removal. When ISS assembly is complete, there will be a total of 9 cooling loops in the US Lab, Node 2, Node 3, JEM and COF. Without a higher $\mathrm{pH}, 9$ to $18 \mathrm{NiRAs}$ total would likely be needed to keep up with nickel concentrations on all 9 coolant loops.

One concern with adding carbonate/bicarbonate buffer to the coolant is its potential to form precipitates with nickel, much as phosphate did. Some trace elements in the coolant, like calcium, will precipitate out immediately. These do not exist in high enough concentrations to be of concern. Additional beaker testing has been performed in which nickel has been added to coolant with the new buffer formulation at temperatures representative of on-orbit operations until a supersaturated condition occurs at which the water turbidity rises substantially. At the lowest temperatures experienced in the IATCS coolant (34F), nickel concentrations in the new buffer can reach as high as 24 ppm without becoming supersaturated and causing precipitate formation. At the temperature that most loads begin to shut down (92F), the nickel concentration can be raised to $7-10 \mathrm{ppm}$ before the turbidity increases. At the maximum allowable temperature of most loop components (120F), the coolant stays clear at $1 \mathrm{ppm}$, but precipitation occurs by the time the nickel concentration reaches $3.5-5 \mathrm{ppm}$. This data will be used to establish criteria for implementation of NiRA after coolant remediation is complete and slow dissolution of nickel begins once again.

At this writing, material compatibility tests are not yet completed, but this buffer is expected to be benign to the IATCS materials of construction. Additionally, it has no effect on coolant viscosity, thus posing no risk to gas trap function.

\section{ANTI-MICROBIALS}

Silver has been shown to be ineffective and have potentially adverse long-term effects on IATCS components. The program has investigated replacement anti-microbials for several years. From the studies of 2003, Glutaralaldehyde was selected for certification and found to be effective, reasonably stable and did not exhibit any materials compatibility issues. Glutaralaldehyde was, however, challenged in implementation due to having a Minimum Inhibitory Concentration (MIC) roughly equivalent to the concentration for which the on-orbit contaminant control systems could maintain the atmospheric 180 day Spacecraft Maximum Allowable Concentration (SMAC). Higher concentrations of Glutaralaldehyde carried 
toxicological and crew health concerns which drove the decision to search for a different anti-microbial.

The program enlisted the help of two teams of outside consultants to perform new surveys of likely antimicrobial candidates in 2004. Ortho-phthaldehyde (OPA) and Kordek, a methyl isothiazolone compound, were eventually selected for evaluation. Through a series of screens and tests, both were evaluated for stability and efficacy against planktonic and biofilm microorganisms. OPA was determined to be very effective against both planktonic and biofilm microorganisms at $20 \mathrm{X}$ the MIC and had acceptable stability, Figure 25 . Additionally, OPA contributed no halogen contaminants, and was not expected to have any material compatibility issues based on its similarity to Glutaralaldehyde. Kordek was determined to also be very effective against planktonic microorganisms, but ineffective against biofilm. Kordek also had acceptable stability and contributed no halogen contaminants. However, there were remaining unknowns and concerns with degradation byproducts, material compatibility and toxicology.

\section{PPM OPA (pH 9.0)}

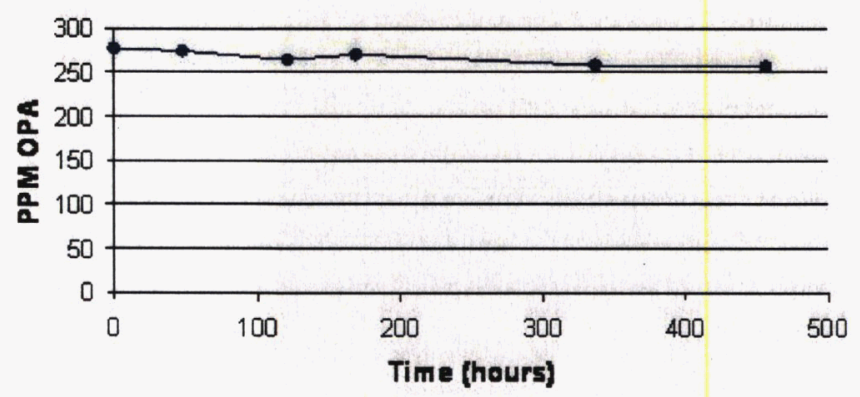

Figure 25. OPA stability at 20X MIC

Based on the evaluation and a risk assessment of proceeding with only a single anti-microbial, OPA was selected as the new anti-microbial. Material compatibility testing will be conducted once the buffer formulation is validated through modeling.

A DOWEX adsorbent resin was selected for delivery of OPA in the on-orbit system. The resin is packaged in a canister (i.e. refurbished NiRA or PhosRA) and provides a precise, safe delivery of the anti-microbial. The onorbit use concentration will be $\sim 100 \mathrm{ppm}$ which is $10 \mathrm{X}$ MIC. The coolant has been assigned a Tox rating of zero for this concentration of OPA.

Measurement of OPA in the on-orbit system will be via test strips, which are also under development, by tailoring existing test strips used in the medical field.

\section{IMPLEMENTATION SCHEDULE}

An overview of the coolant remediation plan and implementation schedule is shown in Figure 26 . The plan calls for a full scale system test in the Marshal
Space Flight Center (MSFC) US Lab Module Simulator beginning with NiRA testing in May 2006. This test is intended to mimic the on-orbit implementation with accelerations where stable equilibrium conditions allow.

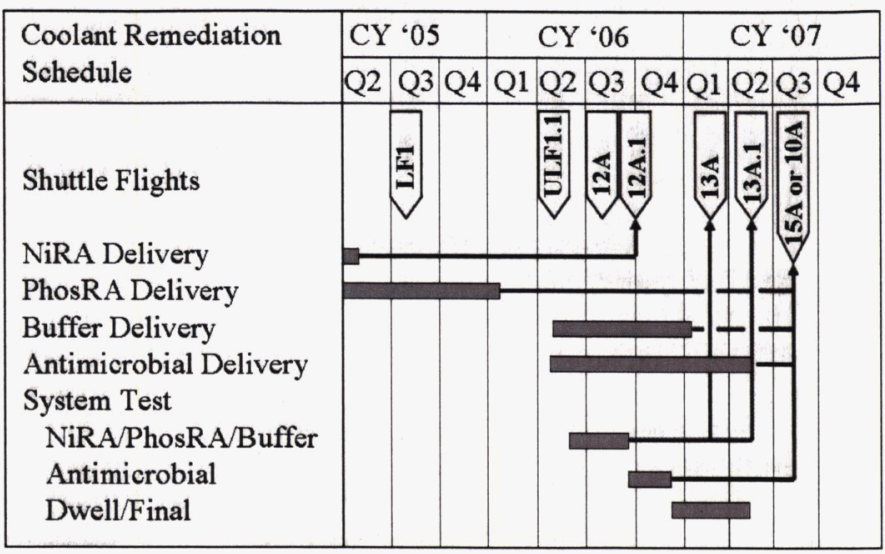

Figure 26. Coolant Remediation Schedule

The planned implementation scheme on-orbit would be to deliver two NiRA units on flight 12A.1 in October 2006. One unit would be installed with the US Lab configured to a single combined coolant loop during the 12A.1 Stage. This unit will stay in the loop for a minimum of 10 days. Within 3 days of removal, a coolant sample will be taken for return on flight $13 \mathrm{~A}$ and the second unit will be installed. The second unit will remain in the loop for a minimum of 40 days and be removed from the loop no more than 6 weeks before flight 13A.1.

Two PhosRA canisters are manifested for launch on 13A.1 in April 2007. Each will be installed for a minimum of 24 hours during 13A.1 docked operations. A coolant sample will be taken before the first PhosRA is installed and after the second PhosRA is removed. Two spent NiRAs, two spent PhosRAs and two coolant samples would then all be returned on flight 13A.1. The PhosRA canisters include a small fraction of NiRA resin to clean out residual nickel that re-dissolves into the coolant after the last NiRA was removed. At this point, the nickel in the US Lab coolant will be at less than $0.2 \mathrm{ppm}$ and the phosphate will be at around $30 \mathrm{ppm}$. There will be some increase in nickel concentration between the end of $13 \mathrm{~A} .1$ and the beginning of the next flight, but its effect on the system is expected to be negligible.

The four canisters returned on flight $13 \mathrm{~A} .1$ will then be refurbished into an additional PhosRA, a Buffer Delivery Assembly (BuDA), an Anti-microbial Addition (AmiA) canister, and an Anti-microbial Removal Assembly (AmiRA). All four devices will be launched on either flight $15 \mathrm{~A}$ or 10A, whichever occurs first, in August 2007.

The PhosRA will be installed on the flight that it is delivered, after taking a coolant sample and during docked operations. This unit also contains a fraction of NiRA resin and will reduce the nickel concentration to 
less than $0.2 \mathrm{ppm}$ while reducing the phosphate concentration to around $10 \mathrm{ppm}$. It will remain in the loop for a minimum of 24 hours and then be removed. The BuDA canister will then be installed in the loop to inject the carbonate / bicarbonate mixture. This will require only a few hours to complete. Finally, the AmiA canister will be installed to deliver the OPA. This will take a couple of hours. This will complete the coolant remediation of the US Lab. The spent PhosRA, BuDA and AmiA canisters will all be returned on the same flight they were delivered.

\section{OTHER ELEMENTS}

It was decided to fill Node 2 with SSP 30573 Rev. B fluid modified to delete the silver and phosphate and lower $\mathrm{pH}$ to 8.4 by sparging with $\mathrm{CO} 2$ in April 2005 . Glutaralaldehyde at $200 \mathrm{ppm}$ was added for microbial control. This coolant is circulated through the Node 2 loops 5 days per week, 8 hours per day using ground support equipment pumps as ground operations allow. Ground NiRA units are installed to remove nickel. The intent is to remove as much intermetallic nickel from Node 2 on the ground as possible, so as to minimize the necessity to use NiRAs in Node 2 on orbit. All hardware life predictions for Node 2 are based on this chemistry and are not an issue. Figures 27 and 28 show the nickel concentrations in the Node 2 loops since this coolant has been added. These demonstrate the effectiveness of the NiRA for controlling nickel in actual flight hardware loops at the on-orbit $\mathrm{pH}$ conditions.

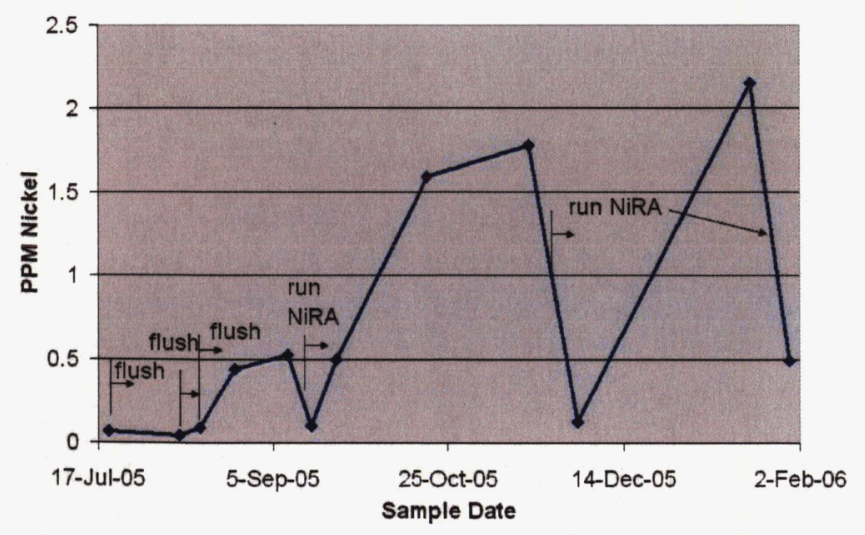

Figure 27. Node 2 LTL Nickel

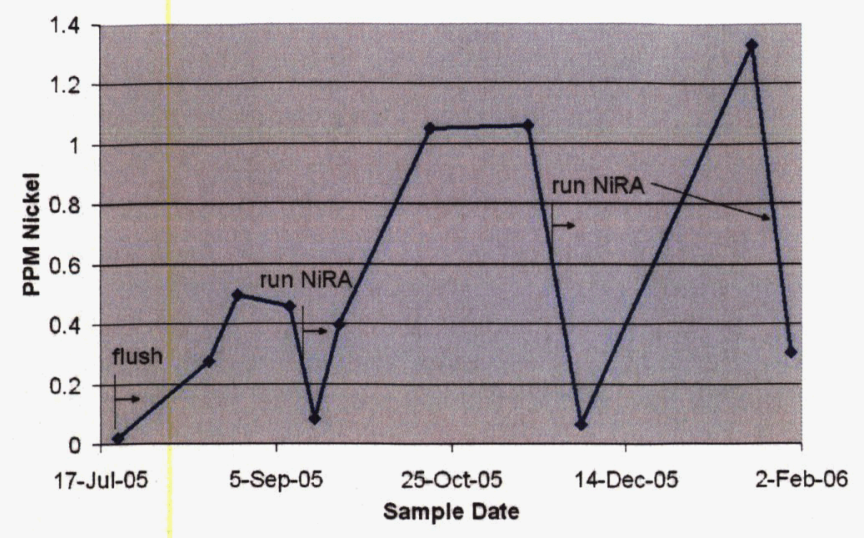

Figure 28. Node 2 MTL Nickel

Just before Node 2 is closed out for launch, this coolant must be replaced with coolant that has the planned onorbit formula.

A new coolant formulation would typically not be introduced into flight hardware prior to completing certification. However, both chemical modeling and material compatibility testing were still in progress in early 2006 and the Node 2 flight closeout schedule would have been impacted without early implementation. A waiver to SSP 30573 requirements was approved allowing the new formulation to be added to the Node 2 IATCS. The waiver was approved on rationale that laboratory testing of the buffer has shown stability and no adverse precipitate formation, and no compatibility issues are anticipated with OPA since earlier materials testing with Glutaralaldehyde, which is more aggressive, was successful.

The coolant defined in the waiver consists of de-ionized water as a basis, with the following additives: $800-1250$ ppm Borate, $1300-1500 \mathrm{ppm}$ sodium carbonate (as $\mathrm{CO}_{3}{ }^{2-}$ ) and $4200-4600 \mathrm{ppm}$ sodium bicarbonate (as $\mathrm{HCO}_{3}{ }^{-}$) and $75-105 \mathrm{ppm}$ OPA. The $\mathrm{pH}$ of the coolant during ground operations will be $9.4-9.5$ and will equilibrate on-orbit to $9.0-9.1$.

Discussions and planning on the new formulation are ongoing with the International Partners. The JEM has already been delivered to KSC and will require changeout of the coolant prior to launch. Discussions with the European Space Agency (ESA) on the COF, which is scheduled to be shipped from Bremen, Germany to KSC sometime in the spring of 2006, has concluded with the decision to wait on completion of certification of the coolant and fill the Columbus IATCS at KSC sometime prior to launch. The flight coolant formulation for these elements will be documented in waivers similar to Node 2 with a plan to eventually document the formulation in a revision to SSP 30573. 


\section{CONCLUSION}

Early program decisions on the use of gas permeable Teflon flexhoses in the IATCS coolant system and the unexpected effects of higher on-orbit $\mathrm{CO}_{2}$ levels have resulted in a lowered coolant $\mathrm{pH}$. This has led to increased rates of corrosion in nickel brazed hardware throughout the system and precipitation events that have affected component performance. The lack of an effective anti-microbial in the IATCS coolant has created increased levels of planktonic and biofilm associated microorganisms. The program is now well entrenched in a comprehensive program of test, analysis and development of the tools and devices required to drive the coolant chemistry to a stable and effective chemistry. The program is in the process of finalizing the implementation details with the ISS operations team and completion of the US Lab coolant remediation is expected by the end of calendar year 2007 .

\section{ACKNOWLEDGEMENTS}

The work described in this paper was performed by NASA and Boeing and it subcontractors under the auspices of the International Space Station contract, NAS15-10000. The authors would like to gratefully acknowledge the tireless efforts of the NASA and Boeing coolant remediation team.

\section{REFERENCES}

1. Patel, V. P., Barido, R., Johnson, B., Ibarra, T., July 2001, "Development of the Internal Thermal Control System (ITCS) for International Space Station (ISS)", SAE Paper 2001-01-2332.
2. Morrison, R. H., Holt, J. M., July 2005, "ISS Internal Active Thermal Control System (IATCS) Coolant Remediation Project", SAE Paper 05ICES-279.

3. Costerton, J.W., Marrie, T.J., and Cheng, K.J.. 1985. Phenomena of bacterial adhesion, p. 3-43. In D.C. Savage and M. Fletcher (ed.), Bacterial Adhesion. Plenum Publishing Corp., New York.

4. Leimkuehler, T. O., Lukens, C., Reeves, D. R., Holt, J. M., July 2003, "Operational Experience with the Internal Thermal Control System Dual-Membrane Gas Trap", SAE Paper 2003-01-2565.

5. Golden, J. L., Pedley, M. D., Varsik, J., Pohlman, M. J., Steele, J. W., Boyce, W. E., Kendig, M. W., Park, W. P., August 2004, "Corrosion Evaluation of $\mathrm{Ni}-201$ and the BNi-2 and BNi-3 Braze Alloys in IATCS Coolant and Deionized Water", D684-1200101, The Boeing Company.

6. Leimkuehler, T. O., Lukens, C., Reeves, D. R., Holt, J. M., July 2004, "Recent Operational Experience with the Internal Thermal Control System DualMembrane Gas Trap", SAE Paper 2004-01-2428.

\section{CONTACT}

Russell H. Morrison

Associate Technical Fellow

The Boeing Company

IATCS Subsystem Problem Resolution Team Co-Lead Russell.h.morrison@boeing.com

Mike Holt

National Aeronautics and Space Administration Marshall Space Flight Center IATCS Subsystem Problem Resolution Team Lead james.m.holt@nasa.gov 